\title{
Age-Related Changes of the Corneal Endothelium and Stroma as Seen in vivo by Specular Microscopy
}

\author{
E. S. SHERRARD, P. NOVAKOVIC and L. SPEEDWELL \\ London
}

\begin{abstract}
Summary
Two age-related changes of the human cornea are revealed in vivo by specular microscopy, (1) loss (and enlargement) of endothelial cells and (2) wrinkling of the posterior corneal layers when the cornea is applanated.

A comparison of the rate of loss of cells and the effect upon the morphology of the endothelium as determined in several studies, indicates that cell loss and enlargement are rapid in the first year of life, slower up to the age of about 25 years, and fairly stable thereafter. In some individuals the remaining cells appear to enlarge regularly and in others irregularly. Posterior wrinkles on applanation of the cornea occur in the adult cornea only, and suggest an increasing rigidity of the stroma with increasing age.
\end{abstract}

There are many reported age-related changes of the morphology of the cornea but this communication is confined to those that can be detected directly or indirectly, in vivo with the specular microscope. It is therefore confined to the endothelium and the stroma.

Before specular microscopy (SM) Kaufman et $a l^{1}$ suggested from the examination of a relatively few dead, fixed and processed corneas from donors of different ages, that the number of cells that compose the endothelial monolayer decreases with increasing age. The inference was that cells are naturally lost throughout life and are not, or are only partially, replaced by mitotic divisions of surviving cells. The result is lateral and often irregular enlargement of the remaining cells. This is in contrast to the findings in most experimental mammals.

Most of the specular microscopical investigations of the in vivo endothelium, which have the potential advantages over histological methods of unlimited material and free selection thereof, conclude that there is a loss of endothelial cells during life, but whether there are periods of peaking and of stability in the rate of such loss is still open to question. Most works also agree that there is a large variation in the cell population density among corneas from the same age group. It has been suggested therefore, that different corneas either lose cells at different rates or begin life with a different number of cells ${ }^{2}$.

\section{Material and method}

The personal observations reported here are extracted from routine large field SM examinations and special studies currently in progress in the Endothelial Specular Photomicrography Clinic at Moorfields Eye Hospital, and the Hospital for Sick Children, Great Ormond Street, London. Although these studies are as yet incomplete and the results will take many years to compile, the number of eyes so far examined compares favourably with some other studies, and a preliminary report comparing the findings to date with published works of others does not seem out of place.

Correspondence to: Emil S. Sherrard, Professorial Unit, Moorfields Eye Hospital, London EC1V 2PD.

From the Department of Clinical Ophthalmology, Institute of ophthalmology, and The Hospital for Sick Children, Great Ormond St., London. 
Cell population densities (CPD), expressed as the number of cells $/ \mathrm{mm}^{2}$ cornea, are taken from the central cornea, but care has been exercised not to count the cells in overlapping fields. CPD estimates were by the fixed frame method. The clearly visible cells in five large field specular photomicrographs, totalling between 1,000 and 2,000 cells, from each cornea were counted. The specular microscope used throughout was the Pocklington (Keeler/ Konan).

The infantile endothelium: less than one year old

Waring et $a l^{\beta}$ state that not all individuals are born with the same number of endothelial cells. However, there seems to be little support for this as the very few studies, histological and SM, which have included infant corneas fail to give CPDs for the very young. Bahn et $a l^{4}$, counted the cells in one cornea each of a 3, 6 and 21 day old infant and found a mean CPD of just over 6,000 cells $/ \mathrm{mm}^{2}$. They then estimated that there was a 45 per cent loss of cells to produce the adult endothelium and suggested that this occurs 'early in postnatal development'.

In current observations we find an average of 4,425 cells $/ \mathrm{mm}^{2}$ in the 35 corneas under one year old so far examined in vivo. The ages range from 6 days to 11 months, and the CPDs from 3,340 to 5,632 cells $/ \mathrm{mm}^{2}$. The youngest does not show the highest cell count nor does the oldest show the lowest (Fig. 1). However, the sampling is poor (since it is currently incomplete). While the scattergraph (Fig. 1) appears to favour a higher CPD in the younger eyes ( 1 week to 4 months) over that in the older eyes (8-11 months) the mean values show a difference of only 5 per cent.

The scatter of individual cell counts is apparent in the first year of life (Fig. 1) and supports the contention that not all corneas begin with the same number of cells. However, if there is a mean cell loss of 45 per cent early in this year ${ }^{4}$, the possibility remains that the scattergraph shows variability of the rate of this loss and not different starting points, or indeed, it may show both.

As seen with the specular microscope in vivo, the endothelium of the infant (Fig. 2) presents a regular mosaic of small, rounded, similar cells. Most of the cells are hexagonal but a few have seven immediate neighbours.

The juvenile endothelium: one to twelve years old

Published studies of the endothelium in chil-

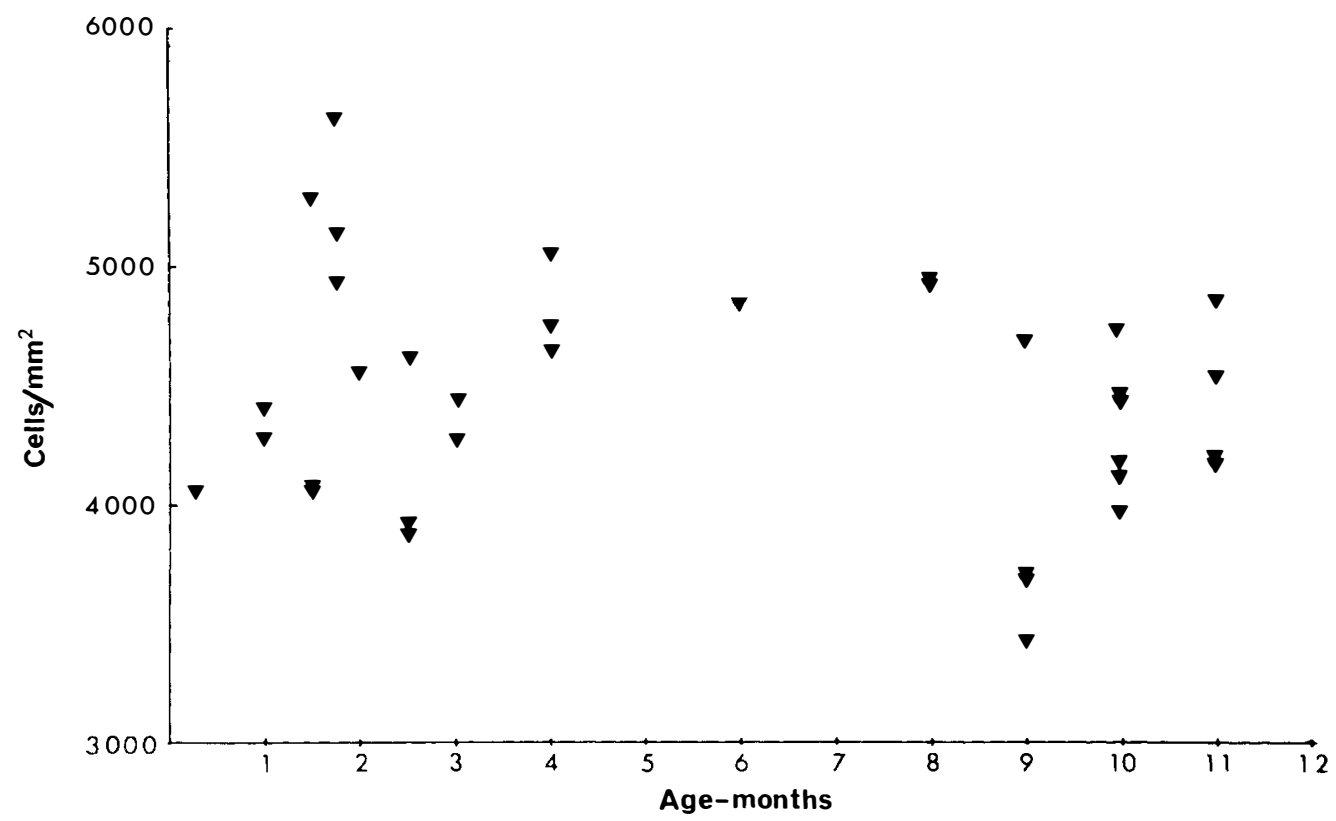

Fig. 1. Scattergraph of endothelial cell counts from 35 corneas aged from 6 days to 11 months. Each point represents the mean count from 5 large field specular photomicrographs from one eye. 


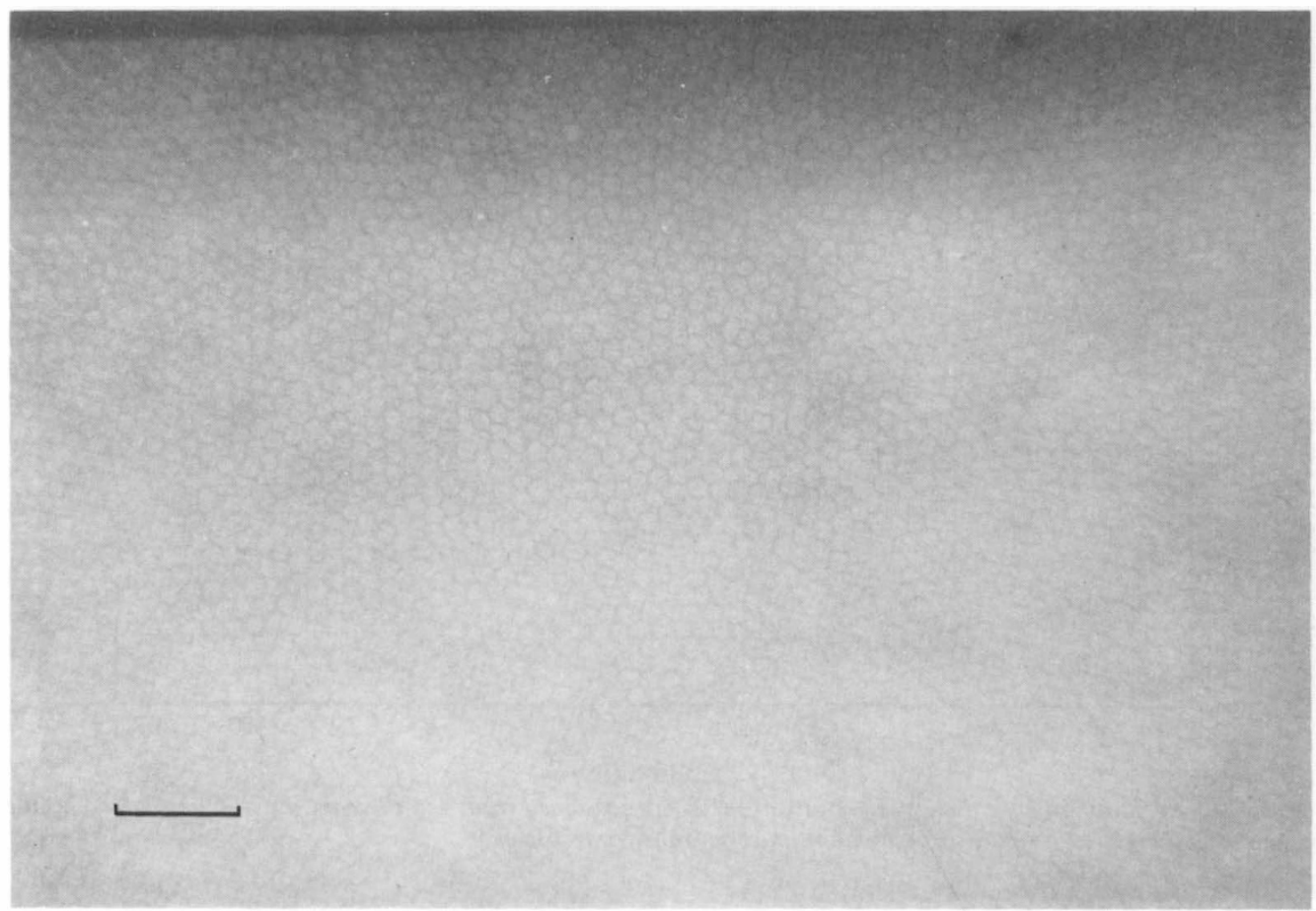

Fig. 2. Specular photomicrograph of corneal endothelium from an 11-month-old baby. The cells are small $\left(4,266 / \mathrm{mm}^{2}\right)$ and rounded. Most are hexagonal, but a few are septagonal. (Bar $=0.1 \mathrm{~mm}$.)

dren are few and usually form a small part of a survey covering all ages. The result is that age samples vary. Laule et al $l^{5}$ includes 15 children under the age of 12 in a study performed with the photoslit lamp. They found that CPD declined steadily and rapidly, from a starting point of 4,450 cells $/ \mathrm{mm}^{2}$ in a three year old, through this age group and up to the age of 25 years, by when 35 per cent of the cells had been lost. Hiles et al $l^{6}$ found a 14 per cent loss from a mean of 3,113 cells $/ \mathrm{mm}^{2}$ in a 0 to 4 year old group to a mean of $2,681 \mathrm{cells} / \mathrm{mm}^{2}$ in a 5 to 9-year-old group, and no loss thereafter, at least to the age of 19 which was the limit of the age range studied.

We find in 24 eyes of children from 4 to 12 years old the range of CPD is from 2,658 to 3,638 cells $/ \mathrm{mm}^{2}$ with a mean of 3,268 cells/ $\mathrm{mm}^{2}$ (Fig. 3). This represents a fall in CPD of about 26 per cent from the CPD in the infants.

The studies with appropriate data find a great scatter of CPDs within the age group of 1 to 12 years. The graph by Hiles et al ${ }^{6}$, based upon 186 eyes, shows that they range from 1,637 cells $/ \mathrm{mm}^{2}$ to 3,900 cells $/ \mathrm{mm}^{2}$.

A graph of our cell counts/age collected so far indicates much less scatter (Fig. 3).

Without estimating the CPD, the mean cell loss from the endothelia in infants is not betrayed by SM changes in children. The cells retain their regularity and roundness.

The adult endothelium: 13 years onward Although most SM studies agree that, based upon mean values, the endothelia of elderly eyes are composed of fewer cells than those of young adults, views differ as to whether there is a trend towards a gradual continuous loss of cells in adult life, or whether there are phases of acceleration and stability of the rate of loss. Laule $e a^{5}$ in their slit lamp study, found that the rapid cell loss through childhood to about 25 years of age, is followed by a slower yet steady decline in CPD which continues until at least the eighth decade.

Works using contact SM and mean values give various results from continuous gradual 


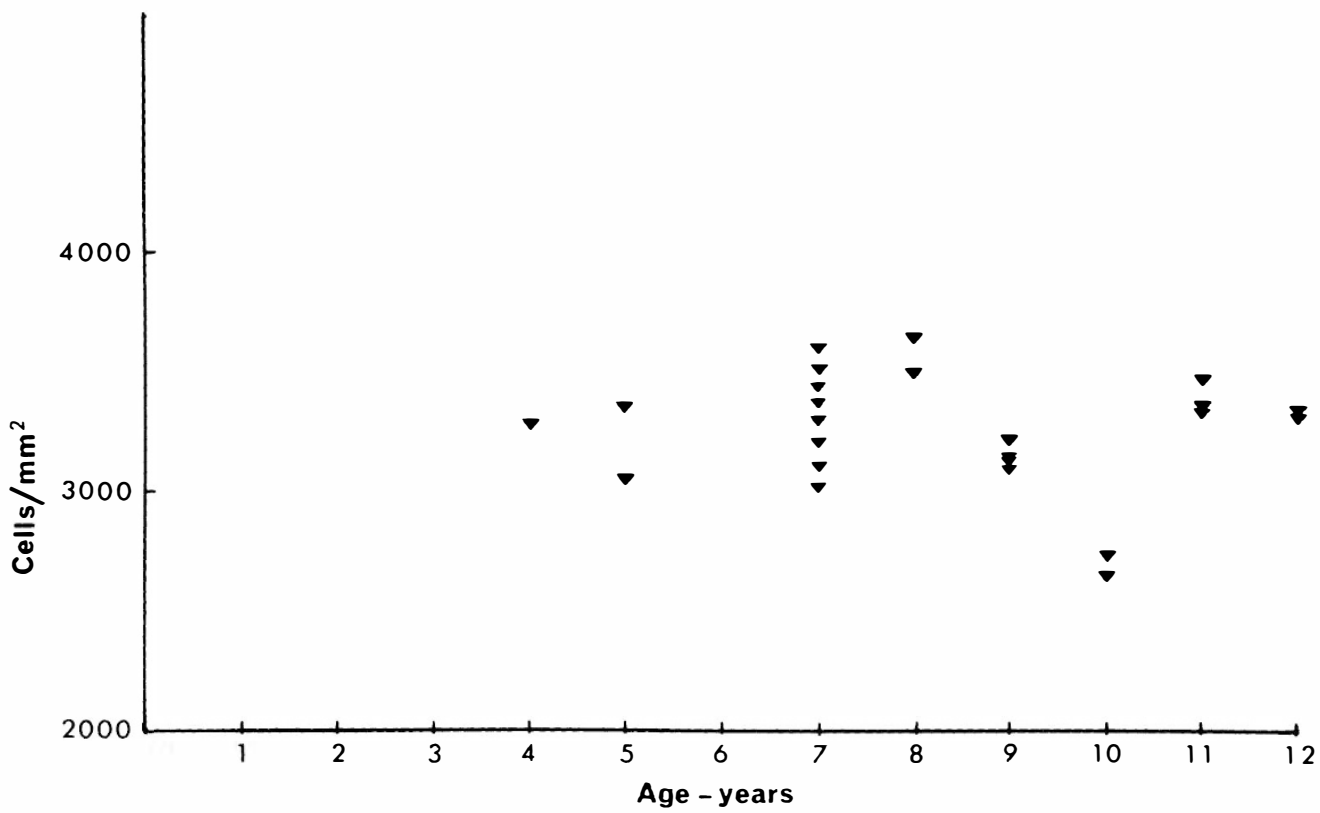

Fig. 3. Scattergraph of endothelial cell counts from 24 corneas aged from 4 to 12 years. Each point represents the mean count from 5 large field specular photomicrographs from one eye.

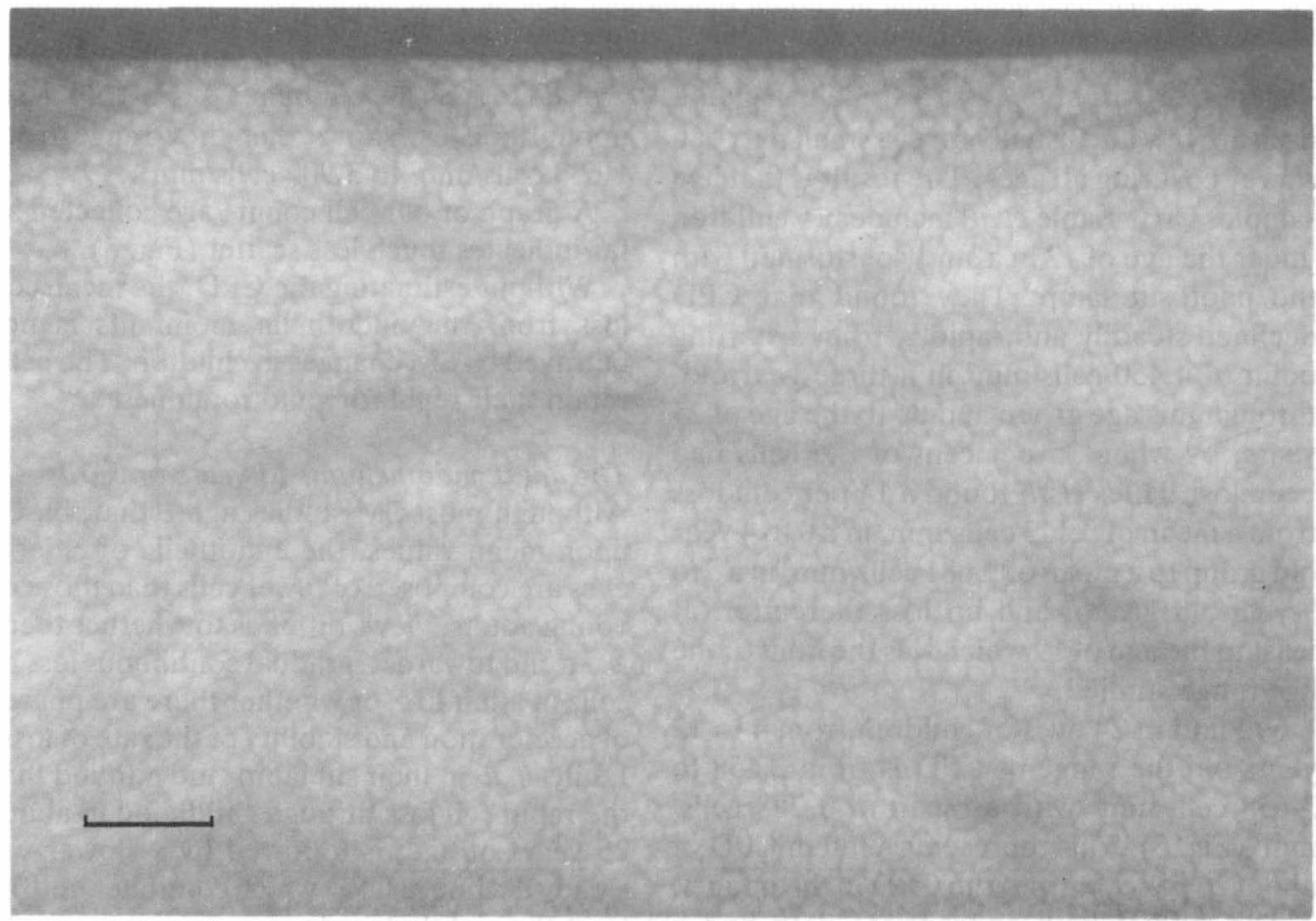

Fig. 4. Specular photomicrograph of corneal endothelium from a 31-year-old man. The cells are visibly larger than in Fig. 2 (shown at same final magnification) $\left(1,926\right.$ cells $\left./ \mathrm{mm}^{2}\right)$ and are fairly uniform in their size and shapes, i.e. a homomegethous endothelium. (Bar $=0.1 \mathrm{~mm}$.) 


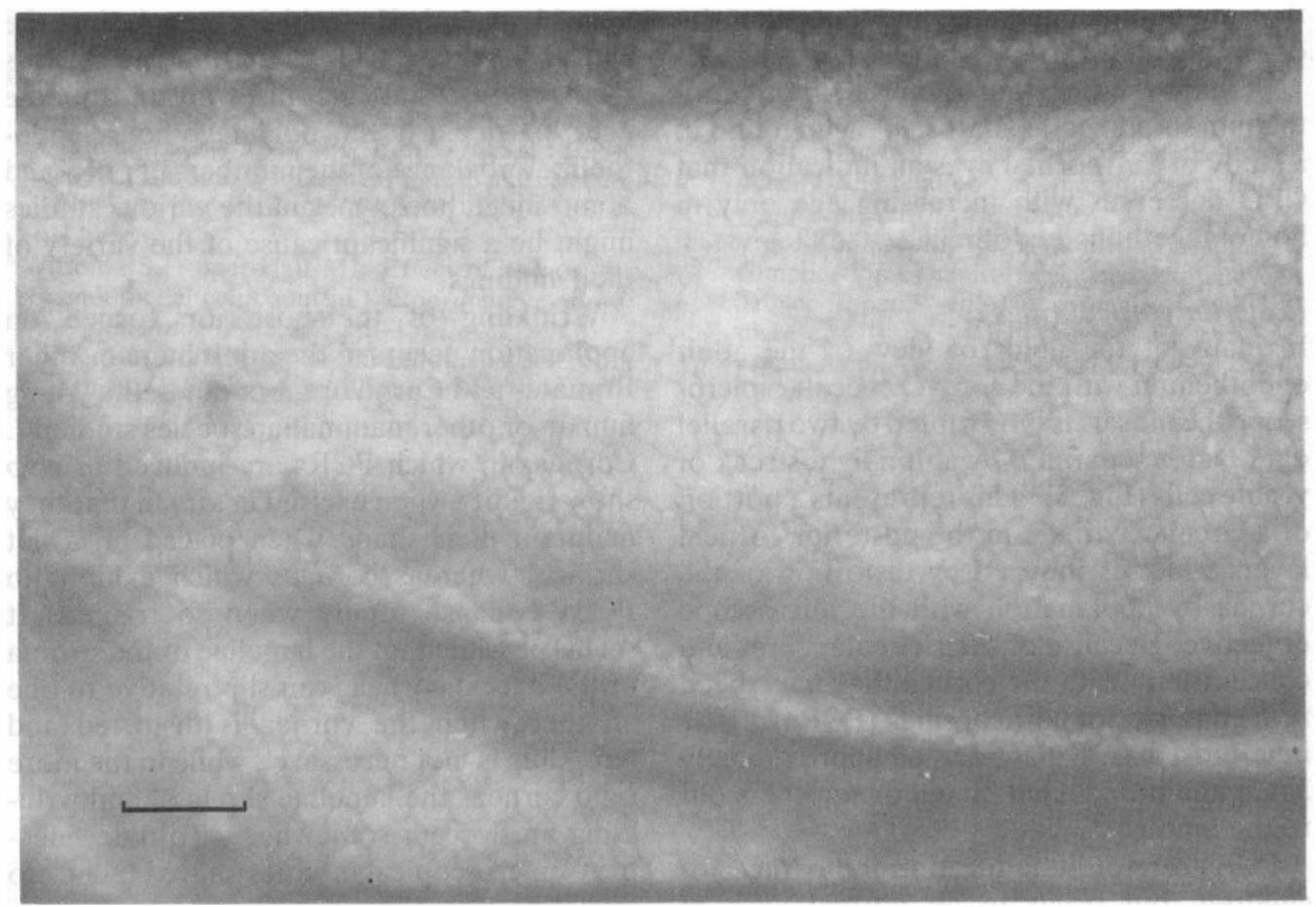

Fig. 5. Specular photomicrograph of corneal endothelium from a 67-year-old man (same final magnification as Figs. 2 and 4). The cells show much variety of size and shape, i.e. a polymegethous endothelium. In the lower part of the picture are two dark, parallel bands separated by a thin streak of endothelium; this represents a portion of a PCR $\left(1,864\right.$ cells $\left./ \mathrm{mm}^{2}\right)$. (Bar $=0.1 \mathrm{~mm}$.)

loss ${ }^{7}$, so that CPD at age 80 is about half that at age $20^{2,8}$; gradual loss to about 50 years of age followed by stability for the rest of life $e^{9.10}$; no further loss after the age of $40^{11}$.

Our own current observations indicate a gradual fall of CPD of 17 per cent between the ages of 20 and 70 .

The CPDs of adult endothelia show as much scatter as in the younger age groups.

Specular microscopically the cells of the adult endothelium (Figs 4 and 5) are more clearly defined and show a wide range of variation in their sizes and shapes between individuals and within an endothelium. Although they are still mostly hexagonal, the lengths of their sides vary and so the regularity of the mosaic seen in children is lost. Usually the increase in cell size over that of the young endothelia is apparent.

Shaw et $a l^{12}$ noted that pleomorphism of the endothelium becomes more marked with age, and they coined the terms 'polymegethism' to describe an endothelium (or part thereof) in which there is gross variation in the sizes of the cells, and 'homomegethism' where the cells are relatively uniform in size. They found that there was no correlation of these two 'forms' with age (those studied were 46 years old or. more), and their CPDs did not differ.

We find that each condition occurs about 50:50 in the asymptomatic eyes of the adult population but we have never found polymegethism in the normal eyes of children. Our youngest cases showing obvious variety of cell size are 18 years old.

Laing et $a l^{8}$ and Waring et $a l^{3}$ have shown with computer assisted morphometric analysis of the endothelium, that with increasing age more cells enlarge to greater sizes, i.e. there is a skew to the right. But, it should be stressed that, just as an endothelium cannot be aged from the CPD because of the tremendous scatter between individuals of the same age, neither can it be aged from its degree of skewness. Not all individuals show skewness, 
they are homomegethous, and those that do, do so to widely differing degrees.

Perhaps the final words on the adult endothelium should go to Blatt et al ${ }^{13}$ who found in a study of 121 normal eyes an indication that CPD decreases with increasing age only in homomegethous endothelia.

\section{Posterior corneal rings}

In many of the fields of view of the adult endothelium with the contact specular microscope the mosaic is interrupted by two parallel dark bands separated by a thin light streak of visible cells (Fig. 5). This represents a portion of a circular wrinkle in the posterior corneal layers which is induced by distortion of the cornea by applanation with the microscope objective. Because of their circular form and concentricity with the cornea they have been termed posterior corneal rings (PCRs). ${ }^{14}$ The innermost has a diameter of approximately $3 \mathrm{~mm}$ and is encircled by ten or so others out to the limbus.

PCRs cannot be induced in the corneas of children, but occur in all normal eyes of adults. They first become evident in corneas of about 25 years old as a series of single dark bands which follow PCR-like circular courses and thereafter develop the double banded appearance. In progressively older eyes the PCRs become progressively complicated by intercommunicating branches.

\section{Discussion}

With the specular microscope two age-related changes of the in vivo human cornea are evident: the enlargement of endothelial cells which results from cell loss, and the occurrence of circular wrinkles on distortion by applanation, which indicates increased rigidity.

Although the figures for the CPDs in each study differ somewhat, and it seems reasonable that this is, at least in part, due to differences in techniques, the age ranges studied and the number of samples in each range, they agree that there is cell loss early in childhood. From a starting point of about 6,000 cells/ $\mathrm{mm}^{2}$, in the first few weeks ${ }^{4}$, about 26 per cent of the cells are lost during the first year of life, accompanied by corneal growth. This is followed by a further 26 per cent loss during the next 11 years, half of which occurs before the age of 5 years $^{6}$. Thereafter, the rate of loss slows and possibly stabilises around middle age, particularly in polymegethous endothelia. Imbalance of the numbers of poly- and homo-megethous types in the various studies might be a significant cause of the variety of their findings.

Wrinkling of the posterior cornea on applanation occurs in the adult human, other Primates and Carnivora, but not in the young human or other mammalian species studied ${ }^{14}$. Corneas in which PCRs are induced in vivo show rigidity when excised in toto in that they maintain their shape when placed on a flat surface, whereas corneas which exhibit no PCRs collapse totally when so treated. It seems possible that the lamellae of the stroma of the flaccid corneas can slip relative to one another when the cornea is distorted and wrinkling is 'not necessary', while in the more rigid corneas the lamellae slip less, and wrinkling must occur somewhere. To date, electron microscopical studies have failed to reveal pertinent differences of ultrastructure between flaccid and rigid corneas.

We thank David Taylor FRCS, Roger Buckley FRCS and Margaret Leigh MRCS LRCP for allowing us to perform specular microscopy on their young patients, and Y. L. Ng PhD for performing most of the endothelial cell counts.

\section{References}

${ }^{1}$ Kaufman HE, Capella JA, Robbins JE: The human corneal endothelium. Am. J. Ophthalmol. 1966; 61: $835-41$.

${ }^{2}$ Sturrock GD, Sherrard ES, Rice NSC: Specular microscopy of the corneal endothelium. Br.J. Ophthalmol. 1978; 62: 809-14.

${ }^{3}$ Waring GO, Bourne WM, Edelhouser HF, Kenyon KR: The corneal endothelium-normal and pathologic structure and function. Ophthalmology 1982; 89: 531-90.

${ }^{4}$ Bahn CF, Glassman RM, MacCallum DK, Lillie JH et al: Postnatal development of corneal endothelium. Invest. Ophthalmol. and Vis. Sci. 1986; 27: 44-51.

${ }^{5}$ Laule A, Cable MK, Hoffman CE, Hanna C: Endothelial cell population changes of human cornea during life. Arch. Ophthalmol. 1978; 96: 2031-5.

${ }^{6}$ Hiles DA, Biglan AW, Fetherolf EC: Central corneal endothelial cell counts in children. Am. Intra-ocular Implant. Soc. 1979; 5: 292-9.

${ }^{7}$ Bourne VM, Kaufman HE: Specular microscopy of 
human corneal endothelium in vivo. Am. J. Ophthalmol. 1976; 81: 319-23.

${ }^{8}$ Laing RA, Sandstrom MM, Berrospi AR, Leibowitz HM: Changes in the corneal endothelium as a function of age. Exp. Eye Res. 1976; 22: 587-94.

${ }^{9}$ Price NC, Barbour DJ: Corneal endothelial cell density in twins. Br. J. Ophthalmol. 1981; 65: 81214.

${ }^{10}$ Wilson RS, Roper-Hall MJ: Effect of age on the endothelial cell count in the normal eye. $B r . J$. Ophthalmol. 1982; 66: 513-15.

${ }^{11}$ Hoffer KJ, Kraff MC: Normal endothelial cell count range. Ophthalmology 1980; 97: 861-6.
${ }^{12}$ Shaw EL, Rao GN, Arthur EJ, Aquavella JV: The functional reserve of corneal endothelium. Am. Acad. Ophthalmol. Otolaryngol. 1978; 85: 640-9.

${ }^{13}$ Blatt HL, Rao GN, Aquavella JV: Endothelial cell density in relation to morphology. Invest. Ophthalmol. 1979; 18: 856-9.

${ }^{14}$ Sherrard ES, Buckley RJ: Endothelial wrinkling: a complication of clinical specular microscopy. In Trevor-Roper P, ed. The cornea in health and disease. Trans. VI Congr. Euro. Soc. Ophthalmol. Acad. Press and Roy. Soc. Med. Series 40. 1981; 69-74. 